\title{
Recurrent somatic embryogenesis and plant regeneration from seedlings of Hepatica nobilis Schreb.
}

\author{
Bożena Szewczyk-Taranek • Bożena Pawłowska
}

Received: 24 February 2014/ Accepted: 18 November 2014/Published online: 9 December 2014

(C) The Author(s) 2014. This article is published with open access at Springerlink.com

\begin{abstract}
A method for secondary somatic embryogenesis was developed on embryos derived from embryogenic callus formed on Hepatica nobilis seedlings. Somatic embryogenesis (SE) was induced on seedlings (on the hypocotyl and epicotyl parts) grown on the Murashige and Skoog (1962) medium (MS) supplemented with $1 \mu \mathrm{M}$ naphthaleneacetic acid (NAA), and/or $0.1 \mu \mathrm{M}$ 6-benzyladenine (BA) and on medium without plant growth regulators (PGR). The best response of embryogenic callus formation was observed on the medium containing $1 \mu \mathrm{M}$ NAA alone or with $0.1 \mu \mathrm{M}$ BA. Individual somatic embryos, formed on embryogenic callus on the medium without PGR (MS0), at heart, torpedo and cotyledonary stage, were transferred to the media where secondary somatic embryo formation and development into plantlets occurred. Although the most efficient repetitive cycles of secondary SE were recorded for all stages of somatic embryos (heart, torpedo, cotyledonary) on the MS0 medium (77.8-87.4\%), secondary somatic embryos were also obtained on all media supplemented with cytokinins. The best rate of somatic embryos germination was achieved on MS media with $0.2 \mu \mathrm{M}$ NAA and $2 \mu \mathrm{M} \mathrm{BA}$, and $0.1 \mu \mathrm{M}$ NAA and $1 \mu \mathrm{M}$ BA $(48.8-52.0 \%)$ when more mature embryos (cotyledonary stage) were used. Plantlets grown from somatic embryos were successfully acclimatized to greenhouse conditions.
\end{abstract}

Keywords Micropropagation - Secondary somatic embryos $\cdot$ Seedling $\cdot$ Hypocotyl $\cdot$ Ranunculaceae

B. Szewczyk-Taranek $(\bowtie) \cdot$ B. Pawłowska

University of Agriculture in Krakow, Al. 29 Listopada 54,

31-425 Kraków, Poland

e-mail: szewczykb@ogr.ur.krakow.pl

\section{Introduction}

The genus Hepatica Mill belongs to the family Ranunculaceae and includes ten species of evergreen hemicryptophytes found in deciduous forests of the Northern Hemisphere. Hepatica nobilis Schreb., called liverleaf, is the most common representative of hepaticas occurring in natural habitat in Europe, Northern America, and Asia. Hepaticas belong to the much celebrated ornamental plants in Japan. Numerous new varieties (derived from $H$. nobilis var. japonica Nakai) with various flower forms, petal colours and foliage types, are the effect of the Japanese breeding programs and are among the most expensive perennials commercially available (Hinkley 2009). It is a very valuable perennial for horticulture and landscape architecture due to the shade tolerance, early spring blooming and decorative evergreen leaves. $H$. nobilis is an indicator species in Poland for meso- and eutrophic deciduous and mixed forests of Querco-Fagetea class. Whole plants have been frequently dug out and transferred from forests to be planted in home gardens, which limited the population and caused disappearance from many habitats (Mirek and Piękoś-Mirkowa 2003). Consequently, since 2004 H. nobilis is strictly protected in Poland (Journal of Laws 2004). Professional propagators of ornamentals are discouraged from wider interest in liverleaf mostly due to difficulties in seed propagation (plants achieve commercial value 3-4 years after sowing), and low multiplication rate when using traditional vegetative methods. There are only a few reports on the in vitro propagation of Hepatica. Induction of adventitious buds on leaf segments of $H$. nobilis var. japonica f. magna was achieved by Nomizu et al. (2003). Leaves from in vitro plants of $H$. nobilis were used to stimulate adventitious bud formation (Szewczyk-Taranek and Pindel 2009). In addition, haploid somatic embryos 
were induced from microspores in anther cultures of liverleaf (Nomizu et al. 2004a).

The objective of the present study was to improve the efficiency of $H$. nobilis in vitro propagation by evaluation the potential of liverleaf somatic embryogenesis (primary and recurrent) and the ability of this plant to regenerate.

\section{Materials and methods}

\section{Source of plant material}

Fresh achenes of $H$. nobilis were collected at the end of May from mother plants (The Live Plant Collection of The University of Agriculture in Krakow, Poland, 50.084416, 19.951413). The next day after harvest the achenes were surface disinfected with $70 \%$ ethanol (60 s), followed by immersion in $5 \%$ sodium hypochlorite (using Domestos) (20 min), and rinsed three times with sterile distilled water. Next, they were placed on $9 \mathrm{~cm}$ Petri dishes (10 per one) filled with $25 \mathrm{ml}$ of MS medium (Murashige and Skoog 1962 ) with $30 \mathrm{~g} \mathrm{dm}^{-3}$ sucrose and $0.7 \%$ agar (Bacto Dif$\mathrm{co}$ ), $\mathrm{pH}$ 5.8. The effect of plant growth regulators (PGRs) was studied in two different media supplemented with $1 \mu \mathrm{M}$ naphthaleneacetic acid (NAA); $1 \mu \mathrm{M}$ NAA and $0.1 \mu \mathrm{M}$ 6-benzyladenine (BA). The third medium without PGR (MS0) was also tested (Table 1). The cultures were maintained at a temperature of $18 / 20{ }^{\circ} \mathrm{C}$ (night/day), under a $16 \mathrm{~h}$ photoperiod, $30 \mu \mathrm{mol} \mathrm{m} \mathrm{m}^{-2} \mathrm{~s}^{-1}$ photosynthetic photon flux density (PPFD) (Philips TL-D $36 \mathrm{~W} / 54$ ) and $80 \%$ relative humidity. The achenes were subcultured into fresh media every 5 weeks. The percentage of seed germination, and formation of somatic embryos and embryogenic callus ( $\%$ of explants) was recorded from the 15 to 20th week of culture. Embryogenic callus (primary somatic embryogenesis-SE) originated from the hypocotyl part of the seedlings cultured on $1 \mu \mathrm{M}$ NAA and $1 \mu \mathrm{M} \mathrm{NAA}+0.1 \mu \mathrm{M}$ BA media were transferred to PGR-free medium.

Secondary somatic embryogenesis

Somatic embryos formed on MS0 were carefully detached at various stages: heart, torpedo, matured cotyledonary stage (with distinct cotyledons) and placed into $9 \mathrm{~cm}$ Petri dishes with four different MS media supplemented with: $1 \mu \mathrm{M}$ BA and $0.1 \mu \mathrm{M}$ NAA; $2 \mu \mathrm{M}$ BA and $0.2 \mu \mathrm{M}$ NAA; $5 \mu \mathrm{M}$ BA and $0.5 \mu \mathrm{M}$ NAA or MS0 (Table 2). All treatments were performed in five replicates, 5-7 explants in each and repeated three times every 4 weeks, as the embryos matured. The culture conditions were the same as for seed germination and somatic embryogenesis. The frequency of secondary somatic embryo formation, embryo maturation and germination was recorded. Properly developed embryos with cotyledons, root and visible bud (next stadium after matured cotyledonary stage), without anomalies were transferred to $100 \mathrm{ml}$ Erlenmeyer flasks filled with $15 \mathrm{ml}$ of MS medium with $2 \mu \mathrm{MBA}$ and $0.2 \mu \mathrm{MNAA}$. For acclimatization, in vitro regenerants were washed from agar, transferred to trays with peatmoss and kept under polyethylene film and white fabric cloth. The temperature was $20{ }^{\circ} \mathrm{C}, 80-90 \%$ of relative humidity and $12 / 12 \mathrm{~h}$ photoperiod, light intensity 60 $\mu \mathrm{mol} \mathrm{m} \mathrm{m}^{-2} \mathrm{~s}^{-1}$ (PHILIPS SON-T AGRO $400 \mathrm{~W}$ lamp). PPFD was increased and humidity decreased by gradually rising the covers after 1 week, for 3 weeks. After 3 months, plants were planted to $9 \mathrm{~cm}$ square pots filled with TS 1 substrate (Klasmann-Deilmann, pH 6.0-6.5) and cultivated in a greenhouse at $25 / 18{ }^{\circ} \mathrm{C}$ (day/night).

For histological examination, callus samples with embryos at various stages were fixed in Carnoy's fluid (60\% ethanol, $30 \%$ chloroform, $10 \%$ glacial acetic acid) overnight, dehydrated in a graded alcohol series, followed by embedding in paraffin $\left(60{ }^{\circ} \mathrm{C}\right.$ for several weeks). Serial Sects. $(8 \mu \mathrm{m}$ thick) were cut with a rotary microtome (Leica RM 2145) and stained in hematoxylin. Section were examined and photographed using a Leica Discovery stereoscope microscope with a digital camera.

Secondary SE results were subjected to analysis of variance (ANOVA). Comparisons of the means were made with Duncan's multiple range test at the $5 \%$ level of probability using the Statistica software (Stat Soft).

\section{Results and discussion}

Zygotic embryos and seedlings are among the most suitable explants for the induction of somatic embryogenesis

Table 1 Induction of primary somatic embryogenesis on $H$. nobilis seedlings

\begin{tabular}{|c|c|c|c|c|c|}
\hline \multirow[t]{2}{*}{ MS media } & \multirow[t]{2}{*}{$\begin{array}{l}\text { Seeds } \\
\text { germination }(\%)\end{array}$} & \multicolumn{2}{|c|}{$\begin{array}{l}\text { Somatic embryos formation } \\
\text { on seedlings }(\%)\end{array}$} & \multicolumn{2}{|c|}{$\begin{array}{l}\text { Embryogenic callus formation } \\
\text { on seedlings }(\%)\end{array}$} \\
\hline & & Hypocotyl & Epicotyl & Hypocotyl & Epicotyl \\
\hline $1 \mu \mathrm{M}$ NAA $+0.1 \mu \mathrm{M}$ BA & 46.0 & 2.0 & 0.0 & 67.5 & 16.3 \\
\hline $1 \mu \mathrm{M}$ NAA & 42.0 & 0.0 & 0.0 & 50.5 & 8.2 \\
\hline PGR-free & 51.0 & 8.1 & 2.0 & 32.8 & 18.3 \\
\hline
\end{tabular}




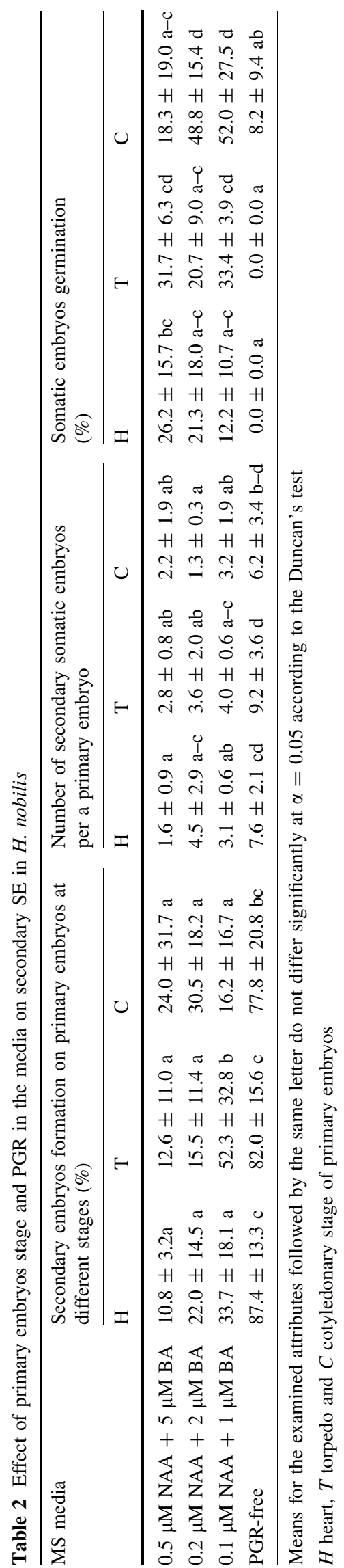

(Raemakers et al. 1995). Seeds of hepaticas are not available on the market, because they have to be sown fresh. They need to be collected from the plant before being dispersed by ants (myrmecochory). Alternating treatments of seeds with warm and cold temperatures in humid conditions are required to complete the embryo growth and germination process. During a period of warm temperatures $\left(15-20{ }^{\circ} \mathrm{C}\right)$ developing embryo reaches the cotyledonary stage and the hypocotyl is expanding. The following stage is the development of the epicotyl, which needs a period of lower temperature (below $10{ }^{\circ} \mathrm{C}$ ) to grow (Baskin and Baskin 1985; Nomizu et al. 2004b). In our experiment, the seeds germinated and formed radicles (42-51\% of seeds) in the 15-20th week of culture, on the medium containing $1 \mu \mathrm{M}$ NAA alone and with $0.1 \mu \mathrm{M}$ BA, and devoid growth regulators (Table 1).

Somatic embryos formed directly on seedlings cultivated on the MS0 medium, both on the hypocotyl (8.1\%) and epicotyl part of plants (2\%) (Table 1; Fig. 1a). Direct somatic embryogenesis was not recorded in medium containing $1 \mu \mathrm{M}$ NAA, however, somatic embryos were observed on the medium supplemented with $1 \mu \mathrm{M}$ NAA and $0.1 \mu \mathrm{M}$ BA, but only on hypocotyls of $2 \%$ of seedlings. Embryogenic callus formation was recorded for all media tested on the epicotyl and hypocotyl part of seedlings $(8.2-67.5 \%)$. The highest efficiency of callus formation $(67.5 \%)$ was observed on the medium containing $1 \mu \mathrm{M}$ NAA and $0.1 \mu \mathrm{M}$ BA (Table 1; Fig. 1b). Hypocotyl was proved by numerous experiments in dicotyledonous plants to be more suitable than other parts of the seedlings as an explant for somatic embryo induction (Raemakers et al. 1995; Pinker and Schenk 2007; Don Palmer and Keller 2011). Typically, seedlings were divided into the cotyledon, hypocotyl and root explants, while in our experiments somatic embryogenesis proceeded on the whole seedlings.

When embryogenic callus was cultivated on PGR-free medium, continuos formation of primary somatic embryo was observed (Fig. 1c, g, h). Somatic embryos collected at various growth stages (globular, torpedo, cotyledonary), were placed on different media for regeneration (Table 2). Efficient formation of somatic embryos (secondary SE) was detected on primary embryos. The highest frequency of SE was reported on MS0 medium, regardless of the developmental stage of primary embryos (77.8-87.4\%). The highest number of somatic embryos per explant was obtained also on MS0 medium (6.2-9.2 secondary embryos per one primary embryo) (Table 2; Fig. 1d, i). Secondary SE was noted in numerous gymnosperm and angiosperm species (Raemakers et al. 1995). Repetitive cycles of secondary somatic embryogenesis on MS0 medium were also observed in Brassica cultures (Pavlović et al. 2013). In our experiments, the culture with the predominance of 

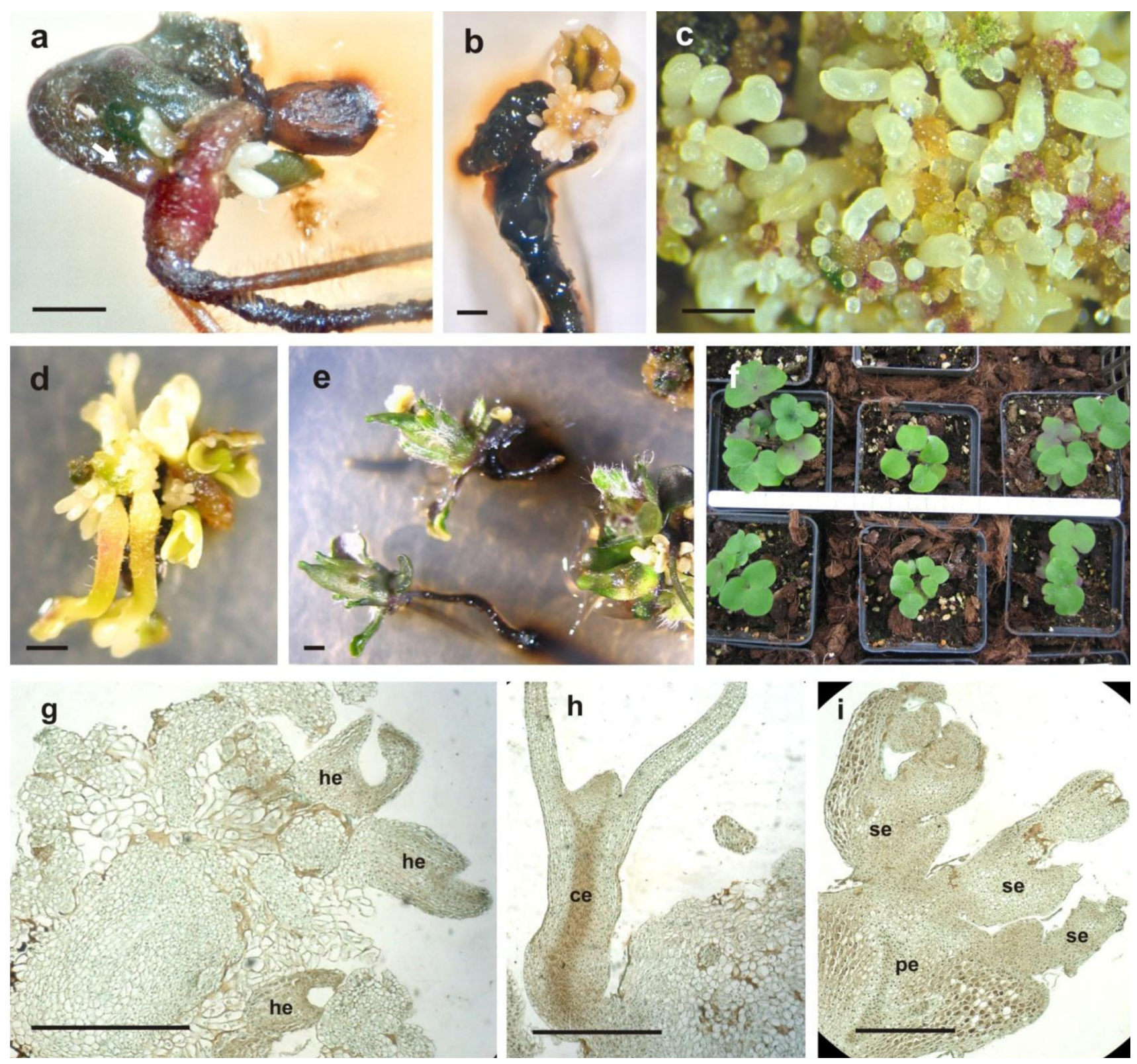

Fig. 1 Somatic embryogenesis (SE) in Hepatica nobilis. Primary SE: direct (a) and indirect (b) SE on the hypocotyl; somatic embryos at various growth stages on embryogenic callus on the MS0 medium (c); Secondary SE: embryos formed on primary embryo at cotyledonary stage on the MS0 medium (d) and on growing primary embryos on

cytokinins reduced the frequency of secondary SE and stimulated germination and plantlet establishment (Table 2). Proper embryo germination was observed when the matured cotyledonary stage was used and cultivated on the MS medium containing $0.2 \mu \mathrm{M}$ NAA and $2 \mu \mathrm{M}$ BA $(48.8 \%)$ or $0.1 \mu \mathrm{M}$ NAA and $1 \mu \mathrm{M}$ BA $(52 \%)$ (Table 2 ; Fig. 1e). Most of the secondary somatic embryos were of good quality, only about $20 \%$ showed abnormalities, like connate roots or multiple cotyledons. Although Nomizu et al. (2003) were able to induced Hepatica embryoids

MS medium with $0.2 \mu \mathrm{M}$ NAA and $2 \mu \mathrm{M}$ BA (e); Five months old plants regenerated from secondary somatic embryos (f); Histological observations: primary embryos at heart (he) (g) and cotyledonary stage (ce) (h) on embryogenic callus, secondary embryos (SE) on primary embryo $(\mathrm{PE})(\mathbf{i})$, bar $=1 \mathrm{~mm}$

directly on leaf segments on the MS medium with 0.1-5 mg L ${ }^{-1} \mathrm{NAA}$ and $0.5-5 \mathrm{mg} \mathrm{L}^{-1} \mathrm{BA}$, these embryos did not regenerate into plants. In our study, secondary embryos at the cotyledonary stage were cultivated on MS medium with $0.2 \mu \mathrm{M}$ NAA and $2 \mu \mathrm{M}$ BA for 15 weeks. The resulting plantlets (62 plants) were adapted to ex vitro conditions, and $40.3 \%$ of them (25 plants) have successfully acclimatized (data not shown, Fig. 1f). In our previous study, we have achieved better acclimatization of Hepatica regenerants, i.e., $65 \%$ of plants regenerated from 
axillary bud culture were adapted to a greenhouse environment (Pawłowska and Szewczyk-Taranek 2007).

An efficient system for induction of primary and secondary somatic embryogenesis and plant regeneration described in our study may contribute to the improvement of the propagation rate of $H$. nobilis, that can be useful in horticulture and breeding.

Acknowledgments This work was supported by statutory funds for science DS3500 granted by the Polish Ministry of Science and Higher Education.

Open Access This article is distributed under the terms of the Creative Commons Attribution License which permits any use, distribution, and reproduction in any medium, provided the original author(s) and the source are credited.

\section{References}

Baskin JM, Baskin CC (1985) Epicotyl dormancy in seed of Cimicifuga racemosa and Hepatica acutiloba. Bull Torrey Bot Club 112(3):253-257

Don Palmer C, Keller WA (2011) Somatic embryogenesis in Crambe abyssinica Hochst. ex R.E. Fries using seedling explants. Plant Cell Tiss Organ Cult 104:91-100

Hinkley DJ (2009) The explorer's garden: rare and unusual perennials. Timber Press, Portland, pp 76-84

Journal of Laws (2004) Dz. U. Nr 92/880, from 16th of April 2004. Nature Conservation Law, Accessed 21 Oct 2014. http://isap. sejm.gov.pl/DetailsServlet?id=WDU20040920880
Mirek Z, Piękoś-Mirkowa H (2003) Flora Polski, Atlas roślin chronionych. Multico, pp 540-541

Murashige T, Skoog F (1962) A revised medium for rapid growth and bioassays with tobacco tissue cultures. Physiol Plant 15:473-497

Nomizu T, Niimi Y, Kasahara S (2003) In vitro micropropagation of 'Yukiwariso' (Hepatica nobilis Schreber var. japonica f. magna) by leaf segment culture. J Jpn Soc Hort Sci 72/3:205-211

Nomizu T, Niimi Y, Han D (2004a) Haploid plant regeneration via embryogenesis from anther cultures of Hepatica nobilis. Plant Cell Tiss Organ Cult 79:307-313

Nomizu T, Niimi Y, Watanabe E (2004b) Embryo development and seed germination of Hepatica nobilis Schreber var. japonica as affected by temperature after sowing. Sci Hortic-Amsterdam 99:345-352

Pavlović S, Vinterhalter B, Zdravković-Korać S, Zdravković J, Cvikić D, Mitić N (2013) Recurrent somatic embryogenesis and plant regeneration from immature zygotic embryos of cabbage (Brassica oleracea var. capitata) and cauliflower (Brassica oleracea var. botrytis). Plant Cell Tiss Organ Cult 113:397-406

Pawłowska B, Szewczyk-Taranek B (2007) Photosynthetic activity of hepatica (Hepatica nobilis Schreb.) propagated in vitro. Rocz AR Pozn 383 Ogrodn 41:153-158 (in Polish, English abstract)

Pinker I, Schenk R (2007) Somatic embryogenesis in Cimicifuga racemosa. Acta Hort 764:265-270

Raemakers CJJM, Jacobsen E, Visser RGF (1995) Secondary embryogenesis and application in plant breeding. Euphytica 81(1):93-107

Szewczyk-Taranek B, Pindel Z (2009) Adventitious buds formation during in vitro micropropagation of noble liverleaf (Hepatica nobilis Schreb.). Zesz Probl Post Nauk Roln 539:701-706 (in Polish, English abstract) 